\title{
Valve gape and exhalant pumping in bivalves: optimization of measurement
}

\author{
A. A. Robson*, G. R. Thomas, C. Garcia de Leaniz, R. P. Wilson
}

Biological Sciences, Institute of Environmental Sustainability, Swansea University, Swansea SA2 8PP, UK

\begin{abstract}
We examined the effect of sampling frequency of gape angle and exhalant pumping measurements on our ability to determine the behaviour of bivalves. We used the endangered freshwater bivalve Margaritifera margaritifera, the non-endangered mussels Mytilus edulis and Mytilus trossulus, the scallop Pecten maximus and the cockle Cerastoderma edule. Increasing sampling interval led to an underestimation of the rate of bivalve gape adduction and abduction events detected, an overestimation of the mean duration between gape adduction and abduction events, and a misunderstanding of the form of the gape adduction and abduction events and exhalant pumping profile. Our analyses suggest minimum appropriate sampling rates for archival tags to define gape behaviour of 2,7 and $40 \mathrm{~Hz}$ in $M$. margaritifera, C. edule and P. maximus, respectively, and $18 \mathrm{~Hz}$ to describe the metachronal wave in exhalant pumping of $M$. edulis. We demonstrate that careful consideration has to be given to the selection of sampling intervals when using a non-continuous method of recording behaviour. Our results emphasize the importance of measuring fine-scale behaviour patterns in order to advance our understanding of bivalves. The potential loss of information associated with the choice of particular sampling intervals during measurements of single parameters, and the biases which can result from this choice, are effectively germane to all species.
\end{abstract}

KEYWORDS: Mytilus spp. · Margaritifera margaritifera · Pecten maximus - Cerastoderma edule · Sampling $\cdot$ Resolution $\cdot$ Recording $\cdot$ Frequency $\cdot$ Behaviour

\section{INTRODUCTION}

Research on bivalve behaviour has produced insights on how organisms cope with highly fluctuating environments (e.g. Jørgensen et al. 1988). Some of the questions addressed have been aimed at providing an overall view of the behaviour of a particular bivalve species. Recording behaviour with high frequency measurements has allowed questions concerning fine-scale bivalve behavioural physiology to be addressed (e.g. Trueman 1966, Hoggarth \& Trueman 1967, Wilson et al. 2005). This may involve assessment of valve gape, siphon movements (changes in aperture), filtration and pumping behaviour in relation to associated environmental parameters such as depth, light, temperature, particulate matter, food availability and predator interactions (e.g. Ropert-Coudert \& Wilson 2004). Although archival tags have elucidated some remarkable animal behaviours (see e.g. Ropert-Coudert \& Wilson 2004 for review), selection of the correct temporal resolution, defined by the sampling interval, is critical to defining the quantity and form of behavioural events (Boyd 1993, Ropert-Coudert \& Wilson 2004). Controversy about many aspects of bivalve behaviour, such as feeding, partly results from difficulties in accurately recording high frequency measurements of bivalve filtration activity (Maire et al. 2007). Maire et al. (2007) also highlight the importance of recording short-term changes in valve gape and exhalant siphon area.

Direct observation of mussel gape and exhalant siphon area (e.g. Newell et al. 2001, Maire et al. 2007) has the advantage of being simple to perform; however, it does not lend itself to situations where turbidity is high or to burrowing bivalves. In addition, the effective resolution of visual-based systems to determine changing parameters and the frequency with which 
observations are conducted may profoundly affect the quality and interpretation of results (e.g. Wilson et al. 2005). The use of animal-attached remote-sensing technology, in particular Hall sensors, to measure bivalve gape (Wilson et al. 2005, Nagai et al. 2006, Robson et al. 2007) circumvents many of these problems because many measurements can be made per second and the animal may live in its normal substrate.

Maire et al. (2007) proposed that images acquired at a frequency of once every $15 \mathrm{~s}$ were sufficient to assess filtration activity precisely in Mytilus galloprovinciallis, although bivalve gape has also been recorded at $5 \mathrm{~Hz}$ (Wilson et al. 2005), $2 \mathrm{~Hz}$ (Robson et al. 2007), $1 \mathrm{~Hz}$ (Nagai et al. 2006) and once every 5 and $10 \mathrm{~min}$ (Riisgård et al. 2006). However, technology now exists for reliably measuring gape angle at a frequency of $32 \mathrm{~Hz}$ (Wilson et al. 2008).

Despite its endangered status, little is known about the behaviour of the endangered freshwater bivalve Margaritifera margaritifera or about how to measure its wellbeing in captivity (but see Trueman 1966). We suggest that archival tag technology (Cooke et al. 2004, RopertCoudert \& Wilson 2004), such as that used by Wilson et al. (2005) on blue mussels Mytilus edulis, could change this by allowing identification of normal and stressed behaviour (Robson et al. 2007). In the present study we examine the effects of using different sampling frequencies on our ability to elucidate the behaviour of bivalves. The prime driver behind this study is the formalization of a methodology that is appropriate to examine - without bias - gape and pumping behaviours (general proxies for activity associated with respiration, feeding, excretion and their associated metabolic processes) of endangered freshwater pearl mussels, non-endangered mussels Mytilus edulis and Mytilus trossulus, scallops Pecten maximus and cockles Cerastoderma edule.

\section{MATERIALS AND METHODS}

Collection and maintenance of bivalves. All research detailed below was conducted in accordance with institutional, national and international guidelines relating to the use of bivalves in research.

Margaritifera margaritifera used in experiments were held at the Environment Agency Wales, Cynrig Hatchery, Brecon, Wales. Pecten maximus were collected from the Bay of Brest, France, and transferred to a flow-through aquarium system within $2 \mathrm{~h}$. Intertidal Mytilus edulis and Cerastoderma edule were collected from Swansea Bay and Gower coast, Wales, UK, respectively, and $M$. trossulus from the coastline outside the Pacific Biological Station, Vancouver Island, Canada, at low tide and transferred to a flow-through aquarium system within $2 \mathrm{~h}$.
Experimental design. To make relative valve gape measurements in $\mathrm{mm}$ between bivalves of different lengths, we used methods developed by Wilson et al. (2005) and modified by Robson et al. (2007) to quantify gape angle in mussels Margaritifera margaritifera, Mytilus edulis, $M$. trossulus, the scallop Pecten maximus and the cockle Cerastoderma edule. However, neither Wilson et al. (2005) or Robson et al. (2007) calibrated all possible gape angles with sensor output and extrapolated bivalve gape calibration curves beyond known limits. Some gape data $>5^{\circ}$ were thus probably overestimated. The valve gape calibration dilemma was avoided in the present study by killing the bivalves or using a muscle relaxant on them after experiments, and calibrating Hall sensor output in $\mathrm{mV}$ to gape $\left(^{\circ}\right)$ over all gape angles (but see Nagai et al. 2006 who used the Hall sensor to measure bivalve gape without the need for calibration). We recommend calibration to ensure best possible accuracy in valve gape measurements.

Briefly, quantifying bivalve gape involved using a Hall sensor (a transducer for magnetic field strength) attached to one shell valve reacting to a magnet attached to the other shell valve. Variance in gaping extent produced a corresponding variance in the magnetic field strength perceived by the Hall sensor (cf. Wilson et al. 2002). This was recorded by an archival tag. Since Hall sensor output is proportional to magnetic field strength and angle of impingement, the transducer output must be calibrated by comparing shell gape angle with sensor output over a wide variety of angles. A muscle relaxant (500 ppm buffered Tricaine methanesulfonate, MS-222) (Lellis et al. 2000) was used on the endangered freshwater pearl mussels Margaritifera margaritifera (note M. margaritifera were not killed) to allow calibration of all possible gape angles with sensor output. The adductor muscle(s) of Mytilus edulis, $M$. trossulus, Pecten maximus and Cerastoderma edule were simply severed with a knife and bivalves were immediately calibrated for gape over all possible gape angles ( $~ 5$ min per bivalve). Subsequently, data of sensor output versus gape angle were curve-fitted (for details see Wilson et al. 2002, 2005, Wilson \& Liebsch 2003, Robson et al. 2007). The curve-fit could then be used to determine any gape angle by converting the transducer output accordingly.

One type of archival logger used was a 13-channel JUV-Log equipped with 12 Hall sensors (Honeywell, SS59E) and 1 temperature transducer. Two other archival loggers used were 7-channel JUV-Logs equipped with 4 Hall sensors (Honeywell, SS59E) and also recorded light (lux), pressure (depth) and temperature $\left({ }^{\circ} \mathrm{C}\right)$. Two further 13-channel loggers had Hall sensors linked to the logger (IMASEN, Driesen and Kern $\mathrm{GmbH}$ ) and also recorded light, pressure and temperature. The 13- and 7-channel JUV archival loggers were powered by four 1.2 V $10 \mathrm{Ah} \mathrm{NiMH} \mathrm{D} \mathrm{cells}$ 
and the IMASEN loggers by two $3.6 \mathrm{~V} \frac{1}{2}$ AA lithium batteries. Each had a $1 \mathrm{~Gb}$ flash random access memory and could be set to record at intervals up to a maximum frequency of 2, 12 and $30 \mathrm{~Hz}$, respectively. The IMASEN and JUV-Log archival loggers had 16 and 22 bit resolution, respectively, both recording gape angle at better than $0.01^{\circ}$. The magnets used were $5 \times$ $5 \times 2 \mathrm{~mm}$ neodymium boron magnets.

Magnets and Hall sensors were glued to Margaritifera margaritifera and Pecten maximus using 5-minute epoxy adhesive (X003, Atlas Polymers) and Araldite ${ }^{\circledR} 90$ Seconds (Huntsman Advanced Materials), respectively. The other bivalves kept in saltwater aquaria during experiments had their systems attached using aquarium sealant $\left(\right.$ Geocel $\left.{ }^{\circledR}\right)$, and the bivalves kept in intertidal environments had systems attached using high strength epoxy adhesive (Power-Fast ${ }^{\circledR}$, Powers Fasteners). M. margaritifera had been in freshwater pumped from a local river for months before experiments began. Mytilus edulis and Cerastoderma edule were placed in an aerated flow-through aquarium system containing edible particulate matter-laden seawater from Swansea Bay for at least 1 mo before being used in aquarium experiments. $P$. maximus were placed in an aerated flowthrough aquarium system containing edible particulate matter-laden seawater from the Bay of Brest for at least a $24 \mathrm{~h}$ before being used in aquarium experiments. Equipped $M$. edulis and $M$. trossulus used in intertidal experiments were returned to the intertidal within $24 \mathrm{~h}$ of initial collection.

Bivalve pumping. Lengths of PVC tubing $(10 \mathrm{~mm}$ diameter, $1.5 \mathrm{~mm}$ wall thickness and lengths of 300 and $25 \mathrm{~mm}$ ) were glued together at right angles using high strength epoxy adhesive (Fig. 1). A Hall sensor was attached (using aquarium sealant) to the outside of the $300 \mathrm{~mm}$ long PVC tube, $60 \mathrm{~mm}$ below the $25 \mathrm{~mm}$ length of tubing (Fig. 1). A vane $60.5 \mathrm{~mm}$ long, $18 \mathrm{~mm}$ wide and $0.05 \mathrm{~mm}$ thick, made of translucent green Silastic ${ }^{\circledR}$ (Dow Corning) or transparent polyethylene, had one end attached to the $\sim 25 \mathrm{~mm}$ long PVC tubing using aquarium sealant (Fig. 1). A $0.1 \mathrm{~g}$ (in air) neodymium boron magnet was attached at the free end of the vane using aquarium sealant so that the magnet and Hall sensor were aligned (Fig. 1). Pumping sensors were kept in a fixed position in mussel tanks using PVC clamps. The study mussel was then placed in relation to the vane so that the water exhaled (from the top $10 \mathrm{~mm}$ of the inhalant siphon and whole of the exhalant siphon) caused the vane to move, bringing the magnet closer to the Hall sensor, thus causing a change in magnetic field intensity perceived by the transducer (in a manner similar to that used for determining gape angle, see above). It was imperative to keep the Hall sensors and magnets from the gape and pumping sensors sufficiently far apart so they did not interact.

In preliminary pumping experiments Mytilus edulis used their foot to move the translucent green Silastic ${ }^{\circledR}$ vane out of the path of their exhalant water current and stuck it to the outside of their shell. This did not occur over 12 mo of continuous pumping experiments using transparent polyethylene as the pumping sensor vane. Thus, transparent polyethylene was used as the pumping sensor vane in the present study. Sampling frequencies of 2 and $30 \mathrm{~Hz}$ were used to record $M$. edulis pumping. The new method for measuring pumping could not be used in strong currents because of the high sensitivity of the sensor. We did not attempt to calibrate the fine temporal and sensor resolution exhalant pumping data because of complications our system could not easily account for. Complications include: (1) Mytilus edulis exhalant pumping can occur from the top of the inhalant siphon in addition to the exhalant siphonthere is no defined barrier to exhalant pumping from the top of the inhalant siphon, and it may not be assumed that inhalant pumping occurs throughout the whole of the inhalant siphon area (and clearly not when

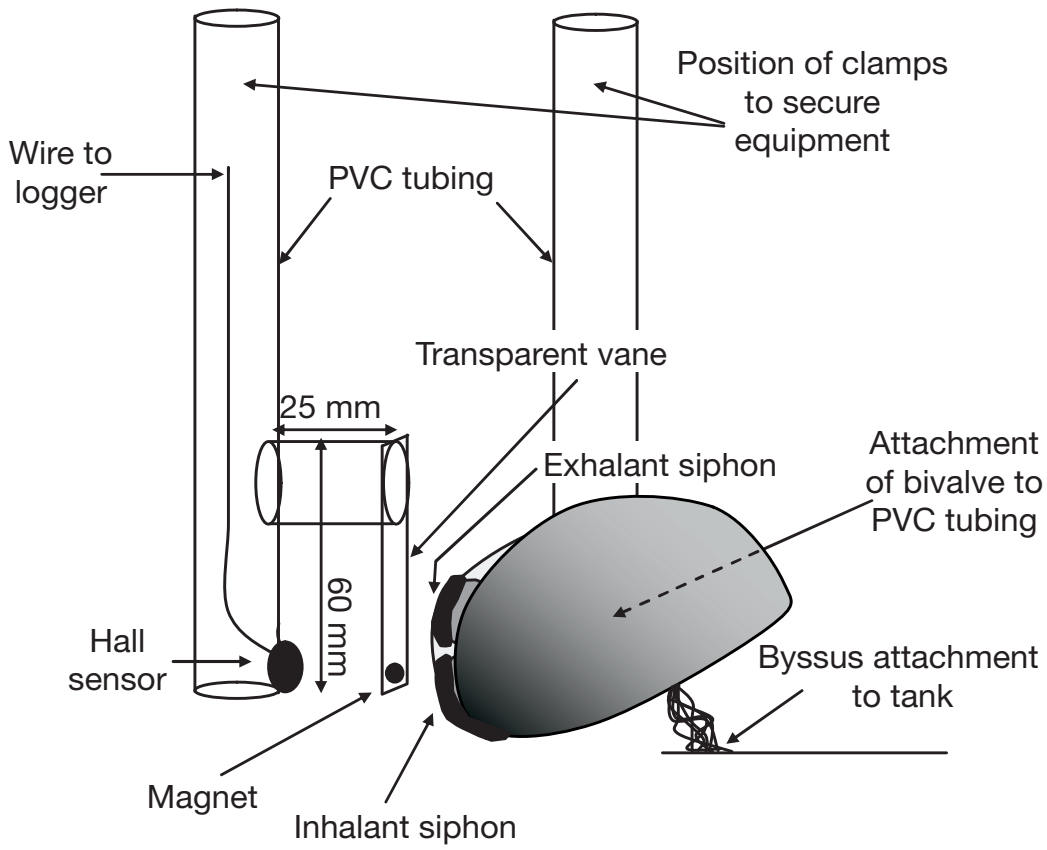

Fig. 1. Mytilus spp. Schematic diagram showing the bivalve pumping sensor for measurement of the flow of water out of the top of the inhalant siphon and whole of the exhalant siphon (aperture). See Wilson et al. (2005) for a schematic diagram showing the attachment of the Hall sensor and magnet system used for determining bivalve gape angle 
exhalant pumping occurs from the top of the inhalant siphon) (2) Both changes in mussel siphon area and siphon orientation relative to the pumping sensor will change the force per unit area exerted on the pumping sensor. (3) M. edulis valve adduction events further complicate the measurement of exhalant pumping because maximum recorded exhalant pumping in this study was not produced by pumping (cilia beat) but by valve adduction (Appendix 1) (thus it is important to also measure valve gape in tandem with exhalant pumping at high temporal and sensor resolution so these two types of currents can be separated).

Experiments. Examples of bivalve gape behaviour at various sampling frequencies in the present study were selected as representative examples from a total of 6 Margaritifera margaritifera, 79 Mytilus edulis (gape and pumping in $48 \mathrm{M}$. edulis), 10 Cerastoderma edule and 7 Pecten maximus in laboratory aquaria as well as 52 Mytilus spp. in the intertidal zone (Atlantic and Pacific). Bivalves in their natural environments fed on natural seston and bivalves in aquarium experiments fed on seston pumped from their natural environment. Experiments with bivalves took place from December 2006 to April 2008.

\section{RESULTS}

\section{Bivalve gape}

In preliminary investigations with live bivalves we made sure that our best-fit gape angle calibration curves for live animals were similar to those for sacrificed individuals. As an example, we used ANCOVA to compare 2 methods of gape calibration repeated in triplicate on one Mytilus edulis: (1) gape calibration on the live mussel and (2) gape calibration after the posterior adductor muscle was severed. Gape calibration method was the fixed factor and gape angle was the continuous variable. There was no significant effect of calibration method in the model $\left(F_{1,39}=0.148, \mathrm{p}=\right.$ 0.702). We reiterate that calibration of maximum gape angle was not possible in live bivalves and highlight that the majority of any error in gape calibration curves was probably caused by human error (all best-fit calibration curves had $\mathrm{r}^{2}>0.98$ ).

All major Mytilus edulis gape movements recorded at $2 \mathrm{~Hz}(0.5 \mathrm{~s})$ followed the same general pattern as those recorded at $30 \mathrm{~Hz}$ (see Fig. 2). The rate of reduction in valve gape angle (adduction) was faster than the subsequent increase in gape angle (abduction), the latter having a roughly logarithmic form, in $M$. edulis (Figs. 2 \& 3), M. trossulus (Fig. 4) and Margaritifera margaritifera (Fig. 5), with the rate decreasing near the endpoints of both adduction and abduction events.

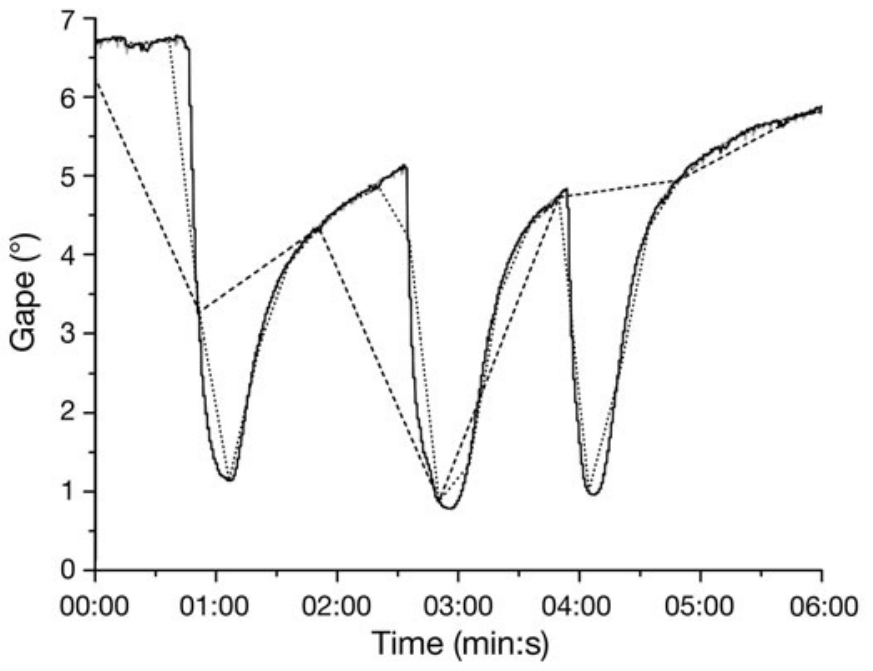

Fig. 2. Mytilus edulis. Example of the effect of sampling frequency on the gape data from a $70 \mathrm{~mm}$ long mussel in an aquarium at Swansea University, UK. Sampling frequencies: $30 \mathrm{~Hz}(-), 2 \mathrm{~Hz}$ (once every $0.5 \mathrm{~s})(-), 0.067 \mathrm{~Hz}$ (once every $15 \mathrm{~s})(\cdots)$ and $0.017 \mathrm{~Hz}$ (once every $60 \mathrm{~s})(---)$. The difference between valve gape recorded at 2 and $30 \mathrm{~Hz}$ is almost indistinguishable except between approximately 00:00 and 00:30 min:s
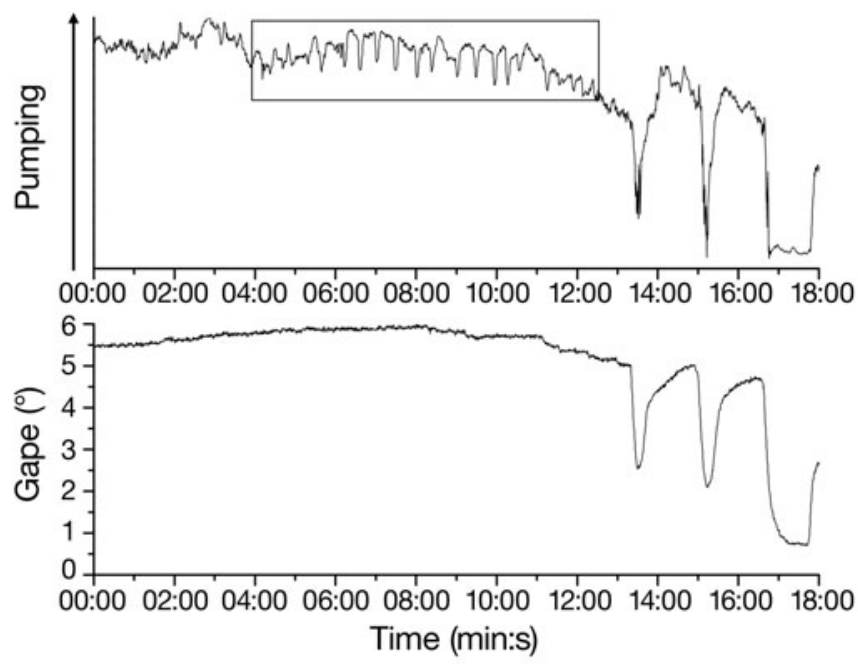

Fig. 3. Mytilus edulis. Detailed example of exhalant pumping and gape data recorded at $2 \mathrm{~Hz}$ from a $72 \mathrm{~mm}$ long mussel in a seawater aquarium at Swansea University, UK. Inset box in top panel highlights poorly defined variation in exhalant pumping

During recording of gape at $2 \mathrm{~Hz}$ in the smaller and faster-moving Cerastoderma edule, the rate of valve abduction did not always decrease near the endpoints of every abduction event (Fig. 6). Close inspection of $C$. edule gape data (Fig. 6) revealed that all valve adduction events occurred at a faster rate than the subsequent abduction event.

Reduction in gape sampling frequency was associated with a progressive change in the shape of the 


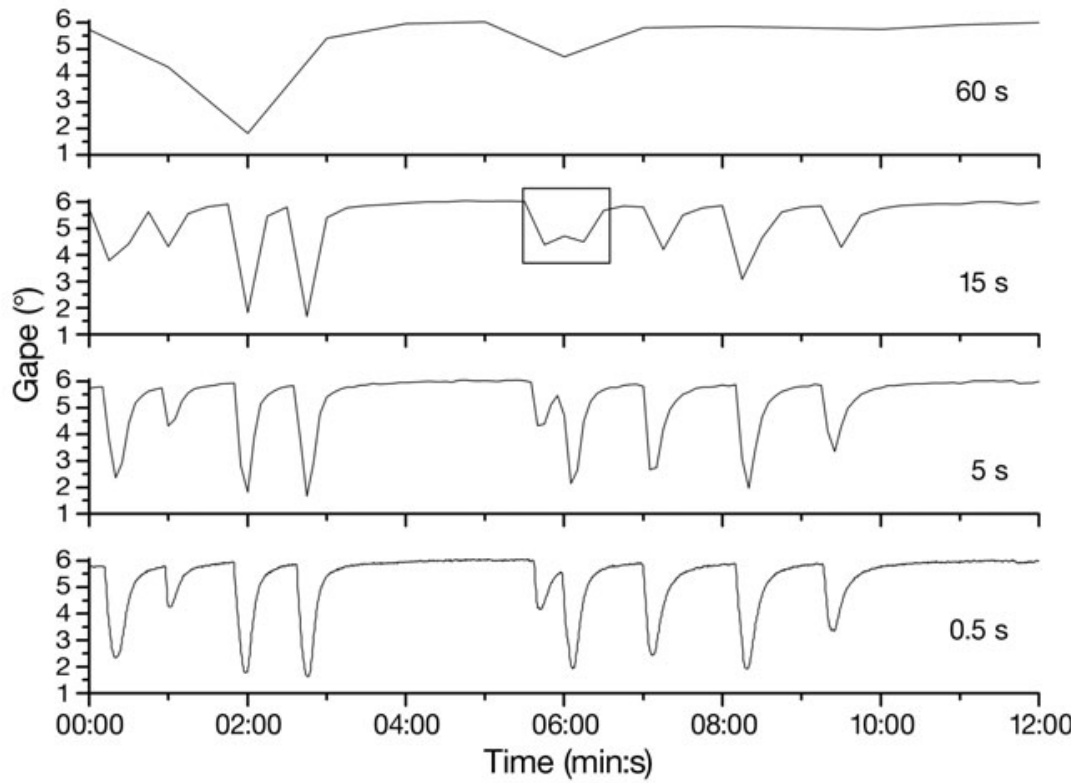

Fig. 4. Mytilus trossulus. Example of the effect of sampling frequency on gape data from a $55 \mathrm{~mm}$ long mussel in the Pacific intertidal zone, Vancouver Island, British Columbia, Canada. Sampling occurred once every 0.5, 5, 15 and $60 \mathrm{~s}$. Box highlights the concatenation of adjacent gape adduction and abduction events in the data record that sampled once every $15 \mathrm{~s}$

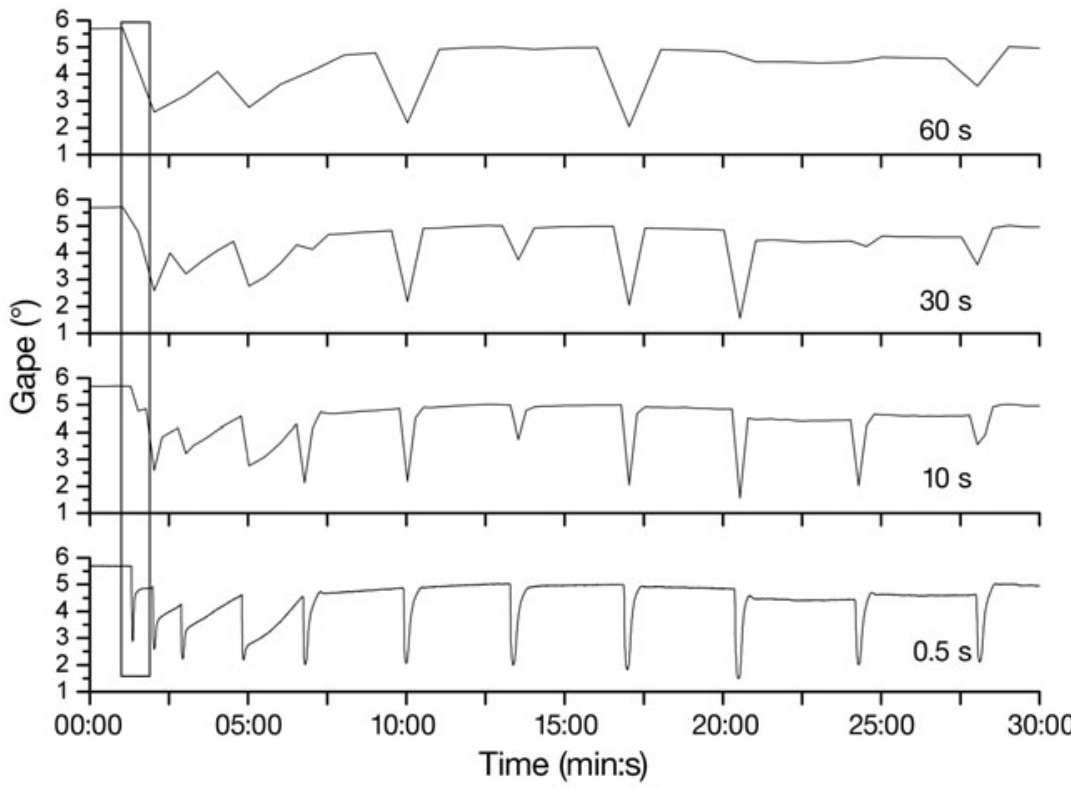

Fig. 5. Margaritifera margaritifera. Example of the effect of sampling frequency on burrowing gape data from a $100 \mathrm{~mm}$ long, freshwater pearl mussel in an aquarium. Sampling occurred once every 0.5, 10, 30 and $60 \mathrm{~s}$. Box highlights the data loss of a valve adduction and subsequent abduction event with decreasing sampling frequency

gape angle versus time graph in both non-burrowing and burrowing bivalves in saltwater aquaria (Figs. 2 \& 6 , respectively) and in wild Pacific intertidal marine bivalves (Fig. 4). Reducing sampling frequency below $2 \mathrm{~Hz}$ (intervals of $0.5 \mathrm{~s}$ ) made valve movements appear to be faster than they actually were (Figs. 2, 4-6).
Accurate assessment of short-term changes in valve gape was only possible recording Margaritifera margaritifera gape at intervals of $\leq 0.5 \mathrm{~s}$ (Fig. 5). Increasing the sampling interval of gape data from 0.5 to $10 \mathrm{~s}$ resulted in the loss of some complete valve adduction and subsequent abduction events (e.g. Fig. 5). Visual observation of $M$. margaritifera burrowing behaviour backed up by recording gape at $0.5 \mathrm{~s}$ intervals (e.g. Fig. 5) highlighted the importance of valve movement for burrowing into sediment.

In one example, sampling at 1 to $5 \mathrm{~s}$ intervals, 45 valve adduction and subsequent abduction events over $1 \mathrm{~h}$ of Margaritifera margaritifera burrowing activity were plotted as a plateau with downward spikes. Increasing the sampling interval to $\geq 10 \mathrm{~s}$ concatenated some adjacent gape adduction and abduction events, with only 10 valve adduction and subsequent abduction events detected when sampling at $60 \mathrm{~s}$ intervals (Fig. 7). Over $1 \mathrm{~h}$ of burrowing activity, mean, median and minimum $M$. margaritifera gape angle increased as the sampling interval increased from 0.5 to $60 \mathrm{~s}$ (Table 1). Increasing the sampling interval from 0.5 to $60 \mathrm{~s}$ caused the interquartile range of $M$. margaritifera gape data to decrease by $0.59^{\circ}$ and caused median gape to increase by $0.31^{\circ}$ (Table 1 ). Maximum gape of $M$. margaritifera and Pecten maxiumus decreased by $0.1^{\circ}$ and $4.72^{\circ}$, respectively, when the sampling interval was reduced from 0.5 to $60 \mathrm{~s}$ (Table 1). Over $1 \mathrm{~h}$ there was no change in mean gape but there was a reduction in maximum gape angle of $M$. margaritifera and Mytilus edulis when the sampling interval was increased from 0.5 to $5 \mathrm{~s}$ (Table 1). Also over $1 \mathrm{~h}$ there was no change in mean gape but there was a reduction in maximum gape angle of Pecten maximus when sampling frequency was decreased from $12 \mathrm{~Hz}$ (sampling interval of $\sim 0.083 \mathrm{~s}$ ) to once every $0.5 \mathrm{~s}$ (Table 1 ). However, over $1 \mathrm{~h}$ of Cerastoderma edule gape data, there was a change in mean gape and a decrease in maximum gape angle when the sampling interval increased from 0.5 to $5 \mathrm{~s}$ (Table 1). 


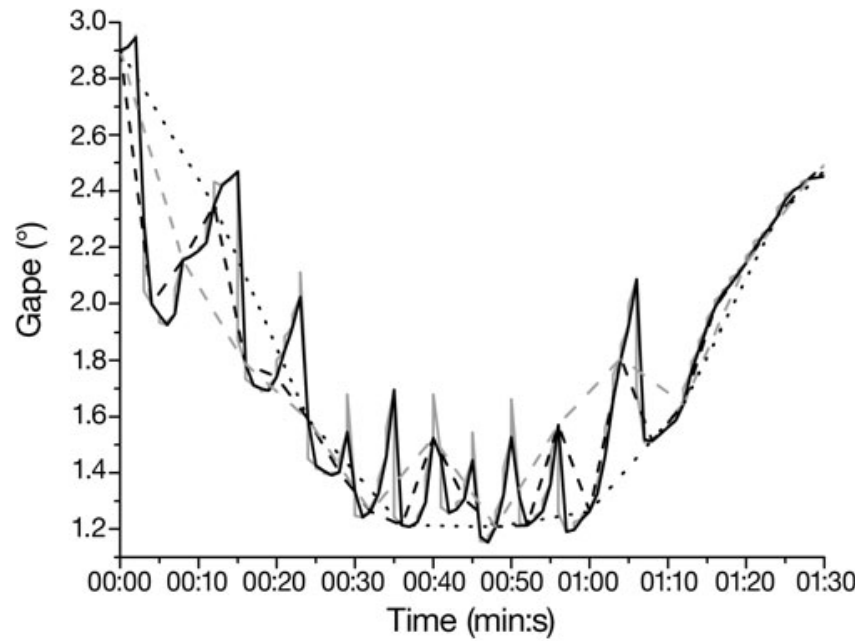

Fig. 6. Cerastoderma edule. Example of the effect of sampling frequency on burrowing gape data from a $30 \mathrm{~mm}$ long cockle in an aquarium at Swansea University, UK. Sampling occurred once every $0.5 \mathrm{~s}(-), 1 \mathrm{~s}(-), 4 \mathrm{~s}(---), 8 \mathrm{~s}$

$$
(---) \text { and } 12 \mathrm{~s}(\cdots)
$$

Table 1. Mean $\pm \mathrm{SD}$, median, maximum, minimum and interquartile range of gape data at different sampling intervals over $1 \mathrm{~h}$ from a burrowing, $100 \mathrm{~mm}$ long freshwater pearl mussel Margaritifera margaritifera in an aquarium, a $110 \mathrm{~mm}$ long scallop Pecten maximus in an aquarium, a $67 \mathrm{~mm}$ long Mytilus edulis immersed in the intertidal zone at Swansea Bay, UK, and a $28 \mathrm{~mm}$ long cockle Cerastoderma edule in an aquarium

\begin{tabular}{|c|c|c|c|c|c|}
\hline \multirow{2}{*}{$\begin{array}{l}\text { Sampling } \\
\text { interval (s) }\end{array}$} & \multicolumn{4}{|c|}{ - Gape $\left(^{\circ}\right)$} & \multirow{2}{*}{$\begin{array}{c}\text { Interquartile } \\
\text { range }\left({ }^{\circ}\right)\end{array}$} \\
\hline & Mean & Median & Max. & Min. & \\
\hline \multicolumn{6}{|c|}{ Margaritifera margaritifera } \\
\hline 0.5 & $3.76 \pm 1.34$ & 3.7 & 5.9 & 0.79 & 2.35 \\
\hline 5 & $3.76 \pm 1.34$ & 3.7 & 5.87 & 0.8 & 2.32 \\
\hline 10 & $3.76 \pm 1.34$ & 3.7 & 5.87 & 0.8 & 2.35 \\
\hline 15 & $3.76 \pm 1.34$ & 3.72 & 5.87 & 0.87 & 2.33 \\
\hline 30 & $3.80 \pm 1.31$ & 3.75 & 5.87 & 0.87 & 2.39 \\
\hline 60 & $3.82 \pm 1.31$ & 4.01 & 5.8 & 0.87 & 1.76 \\
\hline \multicolumn{6}{|c|}{ Pecten maximus } \\
\hline 0.083 & $3.31 \pm 1.58$ & 3.44 & 10.81 & 0.97 & 2.76 \\
\hline 0.5 & $3.31 \pm 1.58$ & 3.44 & 10.69 & 0.97 & 2.76 \\
\hline 5 & $3.30 \pm 1.57$ & 3.53 & 10.03 & 0.98 & 2.76 \\
\hline 10 & $3.31 \pm 1.59$ & 3.39 & 10.03 & 0.98 & 2.76 \\
\hline 15 & $3.29 \pm 1.54$ & 3.54 & 8.52 & 0.98 & 2.75 \\
\hline 30 & $3.27 \pm 1.56$ & 3.11 & 8.52 & 0.98 & 2.74 \\
\hline 60 & $3.25 \pm 1.53$ & 3.02 & 5.97 & 0.98 & 2.83 \\
\hline \multicolumn{6}{|c|}{ Mytilus edulis } \\
\hline 0.5 & $3.28 \pm 0.98$ & 3.15 & 6.27 & 0.45 & 0.41 \\
\hline 5 & $3.28 \pm 0.98$ & 3.15 & 6.24 & 0.48 & 0.4 \\
\hline 10 & $3.28 \pm 0.98$ & 3.15 & 6.24 & 0.56 & 0.4 \\
\hline 15 & $3.28 \pm 0.98$ & 3.16 & 6.19 & 0.72 & 0.41 \\
\hline 30 & $3.28 \pm 0.97$ & 3.15 & 6.19 & 0.72 & 0.41 \\
\hline 60 & $3.29 \pm 0.94$ & 3.16 & 6.09 & 1.37 & 0.35 \\
\hline \multicolumn{6}{|c|}{ Cerastoderma edule } \\
\hline 0.5 & $4.57 \pm 0.52$ & 4.76 & 6.36 & 1.18 & 0.53 \\
\hline 5 & $4.56 \pm 0.54$ & 4.75 & 6.18 & 1.19 & 0.54 \\
\hline 10 & $4.57 \pm 0.54$ & 4.75 & 6.18 & 1.36 & 0.54 \\
\hline 15 & $4.55 \pm 0.57$ & 4.75 & 5.99 & 1.19 & 0.54 \\
\hline 30 & $4.53 \pm 0.60$ & 4.74 & 5.49 & 1.36 & 0.54 \\
\hline 60 & $4.51 \pm 0.67$ & 4.75 & 5.33 & 1.36 & 0.54 \\
\hline
\end{tabular}

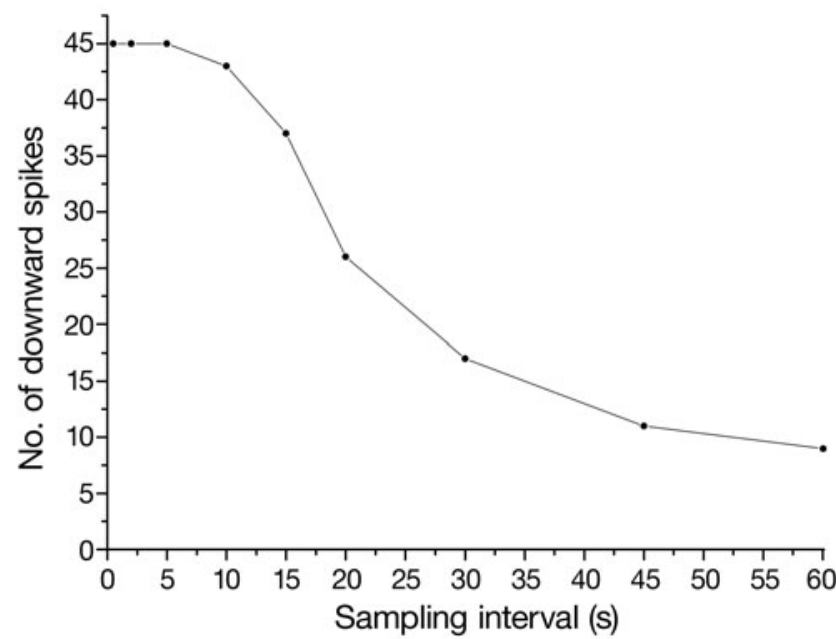

Fig. 7. Margaritifera margaritifera. Example of the effect of sampling interval on the number of detected downward spikes (i.e. valve adduction and subsequent abduction events) during $1 \mathrm{~h}$ of burrowing gape behaviour of a $105 \mathrm{~mm}$ long, freshwater pearl mussel in an aquarium

\section{Pumping}

A reduction in sampling frequency of bivalve pumping behaviour was associated with a loss in definition of short-term changes in exhalant pumping (Fig. 8). At fine scales (2 Hz), Mytilus edulis gape was well defined, while at the same frequency, pumping was apparently rarely constant and did not appear to be fully elucidated (e.g. Fig. 8). Mussel pumping recorded at $30 \mathrm{~Hz}$ revealed apparent and variable noise (a metachronal wave) in the pumping data of all animals (Fig. 9). We determined that the metachronal wave in the pumping data was biological in origin since it was not present when the pumping sensor was used on immersed dead mussels, or when gravity-fed water flowed out of an immersed, modelled mussel exhalant siphon (made from Silastic ${ }^{\circledR}$, Dow Corning) towards the pumping sensor.

\section{Measurements per event}

Recording at $2 \mathrm{~Hz}$, measurements (data points) per valve adduction and subsequent abduction event were counted for 50 events from 6 Margaritifera margaritifera (105 $\pm 1.4 \mathrm{~mm}$ length) and 10 Cerastoderma edule $(28.6 \pm 1.9 \mathrm{~mm}$ length). On average, fewer measurements were made per continuous valve adduction event compared to the subsequent abduction event in both M. margaritifera and C. edule (mean numbers of measurements per adduction and abduction event were 16.0 \pm 5.7 and $44.3 \pm 10.9$, and $4.6 \pm 1.5$ and $9.1 \pm 3.7$ in M. margaritifera and C. edule, respectively), with a minimum of 10 and 3 measurements per adduction event in 

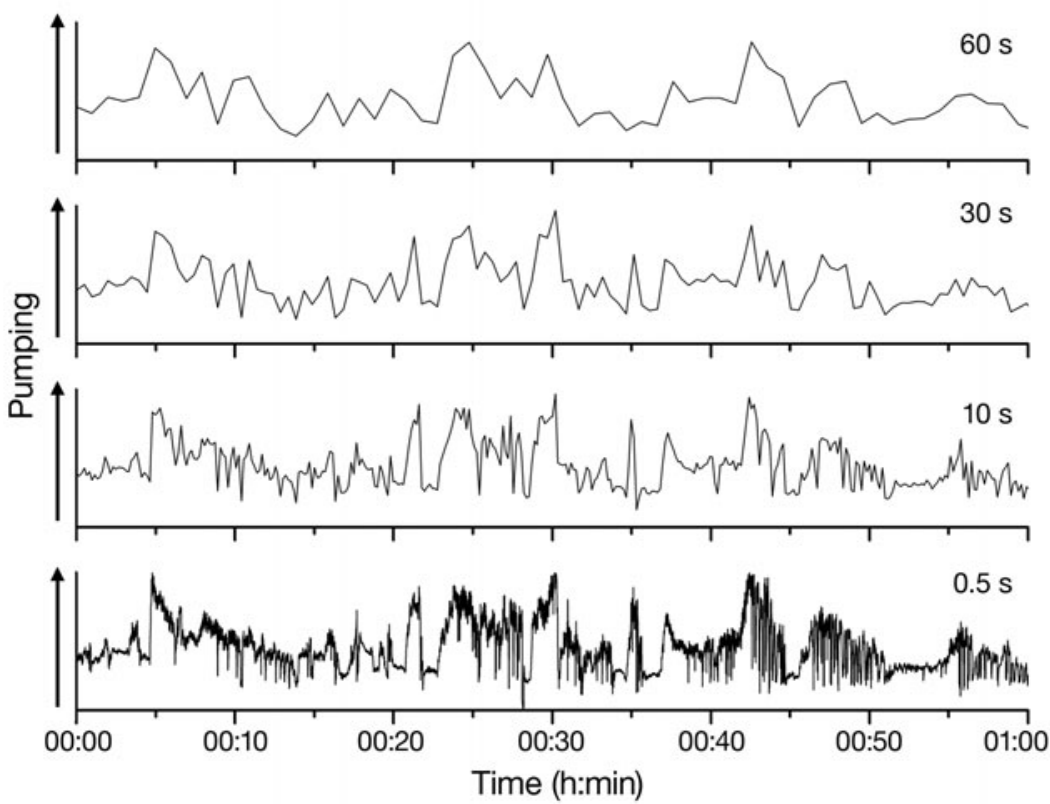

Fig. 8. Mytilus edulis. Example of the effect of sampling frequency on the exhalant pumping data from a $70 \mathrm{~mm}$ long mussel in an auqarium at Swansea University, UK. Sampling frequencies: $0.5,10,30$ and $60 \mathrm{~s}$
780.2, respectively, with a minimum of 3 measurements per adduction event. Complete $P$. maximus valve adduction and subsequent abduction events had a mean number of measurements per event of $1062.4 \pm 766.1$. Recording at $30 \mathrm{~Hz}$, measurements per metachronal wave were counted for 50 metachronal waves from pumping data of 10 Mytilus edulis (69.8 $\pm 1.6 \mathrm{~mm}$ length). A mean of $30.5 \pm 9.4$ measurements was counted per metachronal wave, with a minimum of 17 measurements per wave.

\section{DISCUSSION}

\section{Gape}

The general patterns of Margaritifera margaritifera valve movements recorded at $2 \mathrm{~Hz}$ (e.g. Fig. 5) were the same as those for non-endangered $\mathrm{My}$ tlius spp. (e.g. Figs. 2-4) and as previously described by Robson et al. (2007). Both the present study and the pioneering work by Trueman (1966) and Hoggarth \& Trueman (1967) recorded M. margaritifera valve movements, although we have found no published material on the subject in the interim. We believe that bivalve valve adduction and subsequent abduction events constitute a normal part of bivalve behaviour of both endangered and non-endangered bivalves, occurring in the wild subtidal (e.g. Wilson et al. 2005) and intertidal (Fig. 4), simulated intertidal (Shick et al. 1986) and in laboratory aquariums (e.g. Figs. 2, 3, 5 \& 6; Trueman 1966, Hoggarth \& Trueman 1967, Robson et al. 2007).

Adult Cerastoderma edule are similar in size to the critically endangered little winged pearly mussel Pegias fabula, which rarely exceed $35 \mathrm{~mm}$ in length (Bogan 2002); therefore, gape data from C. edule (Fig. 6) may be a good proxy for small endangered bivalves. C. edule data (Fig. 6) also highlight that there can be greater variability in valve movements of smaller bivalves than in larger bivalves such as Margaritifera margaritifera (Fig. 5), indicating that recording gape of small endangered bivalves at higher frequency (i.e. $>2 \mathrm{~Hz}$, see 'Discussion - Sampling frequency and resolution of bivalve behaviour') may be appropriate (cf. Peters 1983).

Adult Pecten maximus are similar in size $(15 \mathrm{~cm}$ maximum shell diameter) to another marine Pectinid, the IUCN Red Listed Nodipecten magnificus, which commonly approaches $20 \mathrm{~cm}$ in shell diameter (Waller 2007). P. maximus gape data highlight the rapid speed at which this scallop, and probably N. magnificus,
M. margaritifera and C. edule, respectively. Complete M. margaritifera and $C$. edule valve adduction and subsequent abduction events had mean numbers of measurements per event of $54.5 \pm 11.5$ and $14.0 \pm 4.7$, respectively. Recording at $12 \mathrm{~Hz}$, measurements per valve adduction and subsequent abduction event were counted for 50 events from 4 Pecten maximus (107.3 \pm $1.7 \mathrm{~mm}$ length). Mean numbers of measurements per adduction and abduction event were $12.1 \pm 6.8$ and $789.2 \pm$ 
can adduct. The ratios of adductor muscle(s) volume/ weight to shell volume/weight in $P$. maximus will undoubtedly be lower than in Margaritifera margaritifera-although due to their endangered status M.margaritifera could not be sacrificed to quantify the ratios - and may account for the rapid speed of valve adduction in $P$. maximus compared to $M$. margaritifera (see 'Discussion - Sampling frequency and resolution of bivalve behaviour').

\section{Pumping}

Although an accurate quantified measure of exhalant mussel pumping was not possible in the present study (see 'Materials and methods-Bivalve pumping') (cf. Ait Fdil et al. 2006), our results suggest that pumping should be measured over fine temporal scales because we found mussel pumping (and gape) to be often highly variable, even over periods as short as 1 min (cf. Robson et al. 2007). When measuring Margaritifera margaritifera exhalant pumping, especially in relation to gape angle, it may be beneficial to test whether an exhalant current exits from the top of the inhalant siphon as well as the exhalant siphon. Mytilus edulis has a mucociliary rejection pathway that functions via the inhalant siphon with pseudofaeces eliminated along the ventral side of the septum dividing the inhalant siphon from the exhalant siphon (Widdows et al. 1979, Beninger \& St-Jean 1997, Beninger et al. 1999). Along with our own observations of $M$. edulis pseudofaeces strings being eliminated in an exhalant water current out of the top of the inhalant siphon (sometimes when the exhalant siphon was closed), we found it was appropriate to measure exhalant $M$. edulis pumping out of both the top of the inhalant siphon and the entire exhalant siphon.

\section{Biological noise}

Further research is necessary to determine the cause of the biological noise in the form of a metachronal wave of varying amplitude in Mytilus edulis exhalant pumping recorded at $30 \mathrm{~Hz}$ (e.g. Fig. 9). Wilson et al. (2005) reported biological noise in the gape data of bivalves (also present in our gape data) that was consistently higher in sand mussels Astarte borealis than $M$. edulis and suggested that some of it might be due to heart beat (cf. Curtis et al. 2000). While there is little known about the metachronal wave in mussel pumping, it may be an important parameter to measure in bivalves since the frequency of metachronal waves in pumping may vary according to biotic and abiotic factors (e.g. temperature).

\section{Sampling frequency and resolution of bivalve behaviour}

The present study reveals the degree to which intervals between sampling affect our ability to identify bivalve gape adduction and abduction events, the degree of variability in bivalve pumping and, ultimately, how this affects the descriptive statistics of gape and pumping behaviour. One effect of increasing the sampling interval was to concatenate adjacent gape adduction and abduction events in the data record (Figs. 2, 4-7), which resulted in an increased mean duration between gape adduction and abduction events and increased minimum gape angles (Table 1); this is an analogous process to the effect of increasing sampling interval on the diving behaviour of seals (Boyd 1993).

Another effect of increasing the sampling interval was the substantial change to the shape of bivalve gape adduction and abduction events (Figs. 2, 4-6) and pumping profiles (Fig. 8). Increasing the sampling interval from 0.5 to $60 \mathrm{~s}$ had relatively little effect on the mean gape of bivalves (Table 1). However, it was apparent that increasing the sampling interval from 0.5 to $5 \mathrm{~s}$ caused a reduction in maximum gape and thus a loss of definition in short-term changes in bivalve gape (Table 1).

It is essential to select the correct temporal resolution defined by sampling interval in order to detect and define fine-scale behaviour patterns. If the shape of an event is described via changing values in the measured parameter, then the recording frequency should be on the order of 10 measurements per event (RopertCoudert \& Wilson 2004). Given this, our data analysis indicates that gape should be recorded at a minimum of 2, 7 and $40 \mathrm{~Hz}$ in Margaritifera margaritifera, Cerastoderma edule and Pecten maximus, respectively, and at $18 \mathrm{~Hz}$ to describe the metachronal wave in exhalant pumping of Mytilus edulis. Where the peak values in the measured event are important, such as peaks in bivalve pumping amplitudes (Fig. 9) and the exact start and fastest part of valve adduction events, 10 measurements per event may not adequately describe these extremes. We note that some $P$. maximus valve adductions could not be defined (10 measurements per event) with any of the loggers used in the present study or daily diary loggers (Wilson et al. 2008). From our experience measuring bivalve pumping, we speculate that an initial sampling frequency of $30 \mathrm{~Hz}$ would be required to determine the appropriate sampling frequency to measure fine-scale bivalve siphon movements (changes in aperture) of Margaritifera margaritifera.

An inherent problem in dealing with bivalve data measured at high sampling frequency (e.g. 2 to $30 \mathrm{~Hz}$ ) 
over days, weeks and months is data processing time. A computer with $8 \mathrm{~GB}$ RAM and a $3.4 \mathrm{GHz}$ Pentium 4 processor takes $\sim 40$ min to convert 7 million gape data points ( $\sim 64.8 \mathrm{~h}$ and $\sim 40.5 \mathrm{~d}$ of data from an archival tag channel recording at 30 and $2 \mathrm{~Hz}$, respectively) from only one bivalve in $\mathrm{mV}$ to degrees $\left({ }^{\circ}\right)$, using an exponential equation in the form $y=a+b \exp (-x / c)$ in Origin ${ }^{\circledR}$ version 7.5 (OriginLab). A way around this is to thin data so that curve-fits can be applied to much fewer data points. However, too few data points in the time series leads to poor resolution of behaviour which can lead to misinterpretation.

\section{Temporal resolution}

In the present study, with a 1 GB flash memory card and the system set to record at $30 \mathrm{~Hz}$ on 2 channels, recording bivalve gape and pumping simultaneously, the archival tag could record for ca. $70 \mathrm{~d}$ before the memory was full. Using 128 GB compact flash memory cards (Samsung) the recording times of the archival loggers could be multiplied by 128. A computerprogrammed interface could stop the logger just before the memory card was full, the full memory card replaced and logger restarted within $10 \mathrm{~min}$. Thus, it is possible to record high temporal resolution data almost continuously.

\section{CONCLUSIONS}

The potential loss of information associated with the choice of particular sampling intervals during measurements of single parameters, and the biases which can result from this choice, are effectively germane to all species (cf. Boyd 1993). The analyses presented here demonstrate that careful consideration has to be given to the selection of intervals between sampling when using a non-continuous method of recording behaviour. We believe that, where possible, all behavioural events should be recorded because they are likely to vary according to biotic or abiotic factors (e.g. Wilson et al. 2005, Robson et al. 2007). Given that the minimum appropriate sampling frequency has now been established for recording fine-scale Margaritifera margaritifera gape and, most probably, pumping behaviour, our ongoing research can test if the breakthrough in the ability to culture $M$. margaritifera (Preston et al. 2007) can be further improved by conditioning broodstock and providing juveniles with additional food. Advances in the understanding of bivalve feeding and reproductive strategies may be gleaned by recording behaviour with high temporal and sensor resolution over a range of ecological circumstances (according to factors such as depth, light, temperature, particulate matter, food availability and predator interactions) and may aid long-term survival of endangered bivalves including freshwater pearl mussels.

Acknowledgements. This work was funded by the European Social Fund and Deep Dock Ltd. We are grateful to J. Taylor and staff at the Environment Agency Wales; Cynrig Hatchery, Brecon, Wales; C. Pearce and R. Marshall at the Pacific Biological Station, Vancouver Island, British Columbia, Canada; and L. Chauvaud and E. Amice at Laboratoire des Sciences de l'Environnement Marin, Institut Universitaire Européen de la Mer (UMR CNRS 6539), Plouzané, France. Thanks also to L. Halsey, N. Liebsch, J. Houghton, G. Hays, D. Forman, K. Naylor, C. Pooley, J. Brown and J. Wilson for help during the study.

\section{LITERATURE CITED}

Ait Fdil M, Mouabad A, Outzourhit A, Benhra A, Maarouf A, Pihan JC (2006) Valve movement response of the mussel Mytilus galloprovincialis to metals $(\mathrm{Cu}, \mathrm{Hg}, \mathrm{Cd}$ and $\mathrm{Zn})$ and phosphate industry effluents from Moroccan Atlantic coast. Ecotoxicology 15:477-486

Beninger PG, St-Jean SD (1997) The role of mucus in particle processing by suspension-feeding marine bivalves: unifying principles. Mar Biol 129:389-397

Beninger PG, Veniot A, Poussart Y (1999) Principles of pseudofeces rejection on the bivalve mantle: integration in particle processing. Mar Ecol Prog Ser 178:259-269

Bogan AE (2002) Workbook and key to the freshwater bivalves of North Carolina. North Carolina Freshwater Mussel Conservation Partnership, Raleigh, NC

Boyd IL (1993) Selecting sampling frequency for measuring diving behaviour. Mar Mamm Sci 9:424-430

> Cooke SJ, Hinch SG, Wikelski M, Andrews RD, Kuchel LJ, Wolcott TG, Butler PJ (2004) Biotelemetry: a mechanistic approach to ecology. Trends Ecol Evol 19:334-343

Curtis TM, Williamson R, Depledge MH (2000) Simultaneous, long-term monitoring of valve and cardiac activity in the blue mussel Mytilus edulis exposed to copper. Mar Biol 136:837-846

> Hoggarth KR, Trueman ER (1967) Techniques for recording the activity of aquatic invertebrates. Nature 213:1050-1051

> Jørgensen CB, Larsen PS, Møhlenberg F, Riisgård HU (1988) The mussel pump: properties and modelling. Mar Ecol Prog Ser 45:205-216

Lellis WA, Plerhoples TA, Lellis KA (2000) Evaluation of potential anesthetics for the freshwater mussel Elliptio complanata. J Shellfish Res 19:983-990

Maire O, Amouroux JM, Duchene JC, Gremare A (2007) Relationship between filtration activity and food availability in the Mediterranean mussel Mytilus galloprovincialis. Mar Biol 152:1293-1307

Nagai K, Honjo T, Go J, Yamashita H, Oh SJ (2006) Detecting the shellfish killer Heterocapsa circularisquama (Dinophyceae) by measuring bivalve valve activity with a Hall element sensor. Aquaculture 255:395-401

Newell CR, Wildish DJ, MacDonald BA (2001) The effects of velocity and seston concentration on the exhalant siphon area, valve gape and filtration rate of the mussel Mytilus edulis. J Exp Mar Biol Ecol 262:91-111

Peters RH (1983) The ecological implications of body size. Cambridge University Press, Cambridge 
Preston SJ, Keys A, Roberts D (2007) Culturing freshwater pearl mussel Margaritifera margaritifera: a breakthrough in the conservation of an endangered species. Aquat Conserv 17:539-549

Riisgård HU, Lassen J, Kittner C (2006) Valve-gape response times in mussels (Mytilus edulis): effects of laboratory preceding-feeding conditions and in situ tidally induced variation in phytoplankton biomass. J Shellfish Res 25:901-911

Robson A, Wilson R, Garcia de Leaniz C (2007) Mussels flexing their muscles: a new method for quantifying bivalve behaviour. Mar Biol 151:1195-1204

Ropert-Coudert Y, Wilson RP (2004) Subjectivity in bio-logging science: Do logged data mislead? Mem Natl Inst Polar Res 58(Spec Issue):23-33

Shick JM, Gnaiger E, Widdows J, Bayne BL, De Zwaan A (1986) Activity and metabolism in the mussel Mytilus edulis L. during intertidal hypoxia and aerobic recovery. Physiol Zool 59:627-642

Trueman ER (1966) The fluid dynamics of the bivalve molluscs, Mya and Margaritifera. J Exp Biol 45:369-382
Waller TR (2007) The evolutionary and biogeographic origins of the endemic pectinidae (Mollusca: Bivalvia) of the Galapagos Islands. J Paleontol 81:929-950

> Widdows J, Fieth P, Worrall CM (1979) Relationships between seston, available food and feeding activity in the common mussel Mytilus edulis. Mar Biol 50:195-207

Wilson RP, Liebsch N (2003) Up-beat motion in swinging limbs: new insights into assessing movement in free-living aquatic vertebrates. Mar Biol 142:537-547

Wilson RP, Steinfurth A, Ropert-Coudert Y, Kato A, Kurita M (2002) Lip-reading in remote subjects: an attempt to quantify and separate ingestion, breathing and vocalisation in free-living animals using penguins as a model. Mar Biol 140:17-27

Wilson R, Reuter P, Wahl M (2005) Muscling in on mussels: new insights into bivalve behaviour using vertebrate remote-sensing technology. Mar Biol 147:1165-1172

> Wilson RP, Shepard ELC, Liebsch N (2008) Prying into the intimate details of animal lives: use of a daily diary on animals. Endang Species Res 4:123-137

Appendix 1. Mytilus edulis. Example of gape angle and pumping rate of a $75 \mathrm{~mm}$ long mussel. Data recorded at $2 \mathrm{~Hz}$. Arrows: spikes in pumping data caused by the force of rapid valve adductions; *elimination of a faeces string from the exhalant siphon over $\sim 30 \mathrm{~s}$

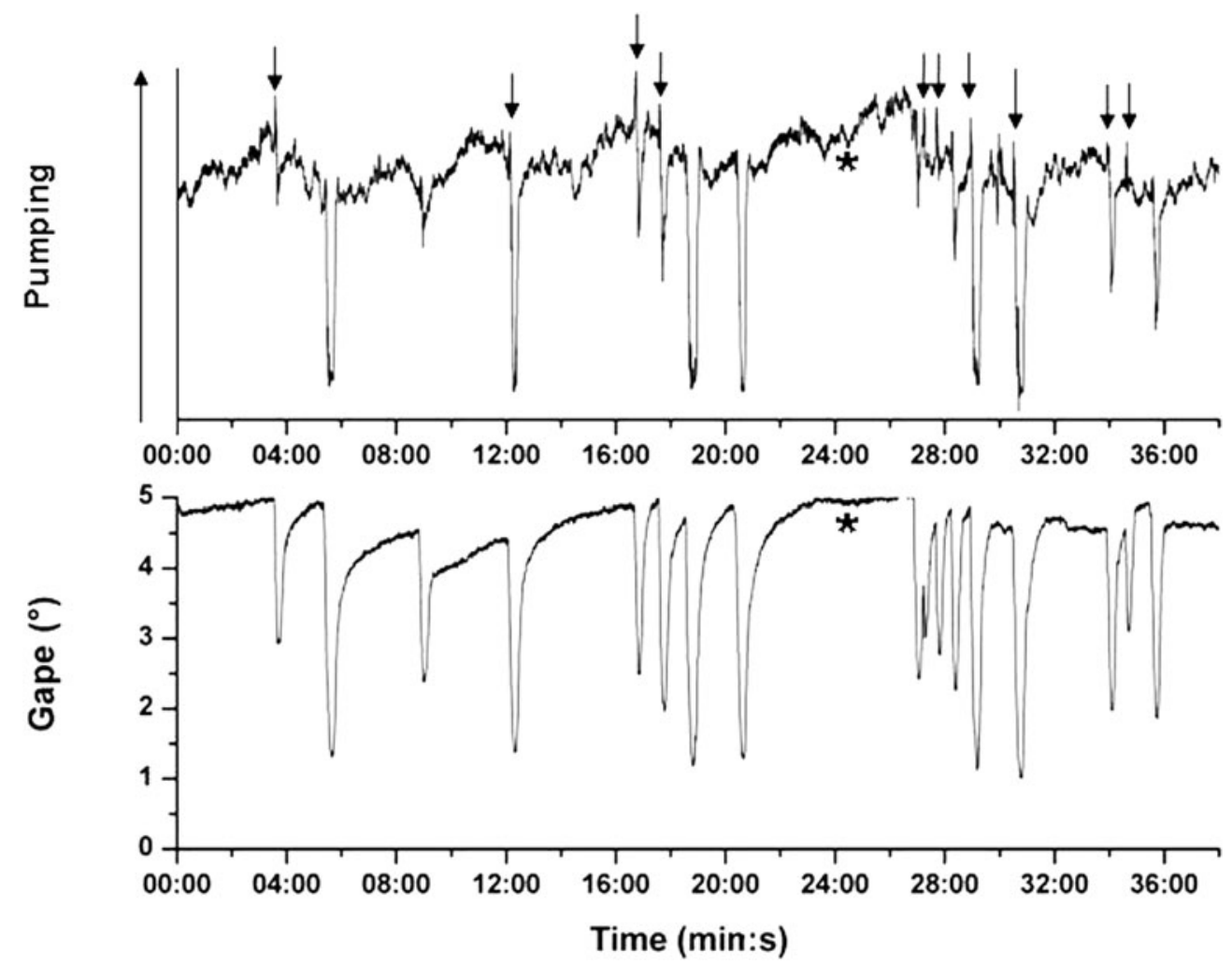

